\title{
OBSOLESCÊNCIA PROGRAMADA E MEIO AMBIENTE: A GERAÇÃO DE RESÍDUOS DE EQUIPAMENTOS ELETROELETRÔNICOS
}

\author{
Valéria Rossini ${ }^{1}$ \\ Samyra Haydêe Dal Farra Naspolini ${ }^{2}$
}

RESUMO:

A obsolescência programada incrementa a produção e o consumo. O objetivo deste artigo é analisar a obsolescência programada e suas consequências ambientais sob o ponto de vista da geração de resíduos de equipamentos eletroeletrônicos. Discute-se a efetividade da política nacional de resíduos sólidos diante do aumento da geração de e-lixo provocado pelos atuais padrões de produção e consumo. Conclui-se que a atual legislação sobre resíduos sólidos ainda não apresenta eficácia para solucionar a crescente geração de e-lixo e que logística reversa e conscientização do consumidor ainda são incipientes no brasil. Utilizou-se o método dedutivo e a técnica de documentação indireta.

Palavras-chave: obsolescência programada; meio ambiente; resíduos de equipamentus eletroeletrônicos; e-lixo; política nacional de resíduos sólidos.

\section{OBSOLESCENCE PLANNED AND THE ENVIRONMENT: THE GENERATION OF WASTE OF ELECTROLETRIC EQUIPMENT}

\begin{abstract}
The planned obsolescence increases the production and consumption. The purpose of this article is to analyze the planned obsolescence and its environmental consequences from the point of view of the generation of waste electrical and electronic equipment. Discusses the effectiveness of the National Solid Waste Policy in the face of increased e-waste generated by current production and consumption patterns. It is concluded that the current legislation on solid waste is not effective in solving the growing generation of e-waste and that reverse logistics and consumer awareness are incipient in Brazil. It was used the deductive method and indirect documentation technique.
\end{abstract}

Keywords: Planned obsolescence; Environment; Waste electrical and electronic equipment; E-waste; National Policy of Solid Waste.

\section{INTRODUÇÃO}

\footnotetext{
1 Mestranda em Direito pela Universidade Nove de Julho - UNINOVE, linha de pesquisa: Empresa, Sustentabilidade e Funcionalização do Direito. Especialista em Direito Ambiental pela FISG - Faculdade Internacional Signorelli. Graduada em Direito pela UNINOVE e em Publicidade e Propaganda pela FAAP Fundação Armando Álvares Penteado.

2 Doutorado em Direito pela Pontifícia Universidade Católica de São Paulo (PUC-SP). Mestrado em Direito pela Universidade Federal de Santa Catarina (UFSC). Pesquisadora e professora permanente do Mestrado em Direito da Universidade Nove de Julho - UNINOVE, cuja área de concentração é Justiça, Empresa e Sustentabilidade. Pesquisadora e professora permanente do Mestrado e Doutorado em Direito da Universidade de Marília UNIMAR. Atua na Escola Superior do Ministério Público de São Paulo desenvolvendo as linhas e grupos de pesquisa da Escola.
} 
A obsolescência programada é um tema multidisciplinar que envolve áreas variadas de conhecimento como Direito, Economia, Engenharia, Propaganda e Marketing. No Direito, a abordagem deste tema é frequentemente realizada pelo viés do direito do consumidor, entretanto suas consequências são mais profundas e estão relacionadas ao meio ambiente.

O avanço tecnológico possibilita a rapidez de informação e comunicação, bem como a rápida superação das inovações, um novo produto tecnológico substitui o anterior em ritmo cada vez mais acelerado. A globalização transforma o mundo em uma "aldeia global"; as empresas tornam-se multinacionais; os mercados, globais; os problemas deixam de ser regionais e tornam-se assunto mundial.

O consumo desmedido, impulsionado pela obsolescência programada, traz consequências para todo o planeta, porque colabora para a continuidade de um estilo de produção que se revela insustentável frente à necessidade de preservação do meio ambiente para a dignidade de vida das futuras gerações.

O tema deste artigo é a obsolescência programada analisada do ponto de vista da geração de resíduos de equipamentos eletroeletrônicos (REE), também chamados de lixo eletrônico, lixo tecnológico ou e-lixo. Será abordada a efetividade da Política Nacional de Resíduos Sólidos (PNRS), instituída pela Lei $\mathrm{n}^{\circ}$ 12.305/2010, diante da problemática do aumento da geração de e-lixo provocado pelos atuais padrões de produção e consumo, que são incompatíveis com o desenvolvimento sustentável.

O presente trabalho torna-se necessário e justificável visto que a obsolescência programada é pouco discutida e apenas por meio da compreensão dos diversos aspectos a ela relacionados, como a geração de resíduos eletroeletrônicos, poderão ser buscadas soluções efetivas para as consequências geradas na atualidade.

No item 1 serão abordados, primeiramente, o conceito e o histórico da obsolescência programada como estratégia empresarial de crescimento, que contou com o solo fértil do Estado capitalista.

O sistema de produção capitalista e a sociedade de consumo, com seu estilo de vida hiperconsumistas e sua relação com a vertente perceptiva da obsolescência, serão analisados no segundo subitem, para compreensão da interligação existente entre eles.

No item 2, primeiramente, serão investigadas as consequências ambientais resultantes do atual modo de produção, que procura acelerar a substituição de produtos incentivando o descarte desnecessário. 


\section{Obsolescência programada e meio ambiente: a geração de resíduos de equipamentos eletroeletrônicos}

A geração dos resíduos eletroeletrônicos, sua composição, riscos ao meio ambiente e ritmo de produção serão analisados, no segundo subitem, bem como as projeções e metas dos Objetivos do Desenvolvimento Sustentável (ODS) da Organização das Nações Unidas (ONU).

Finalizando, no terceiro subitem será estudada a Política Nacional de Resíduos Sólidos (PNRS), pela análise dos instrumentos do sistema de logística reversa e a implementação da responsabilidade compartilhada pelo ciclo de vida dos produtos, previstos nos art. $8^{\circ}$, III e 33, caput e VI, da Lei $\mathrm{n}^{\circ} 12.305 / 2010$, diante da problemática do aumento da geração do e-lixo provocados pelos atuais padrões de produção e consumo.

Para tanto, adotará o método hipotético-dedutivo, utilizando como técnica de pesquisa a documentação indireta por meio de livros, artigos científicos, declarações internacionais sobre meio ambiente e doutrinas jurídicas. Também utilizará o método indutivo para o estudo de dados estatísticos de organizações internacionais ou órgãos públicos e instituições privadas encontrados na rede Internet.

\section{OBSOLESCÊNCIA PROGRAMADA: PRODUÇÃO E CONSUMO GLOBALIZADOS}

\subsection{Obsolescência programada: conceito e histórico}

O significado de obsolescência, conforme o dicionário Houaiss, é tornar algo obsoleto, antigo, antiquado, ultrapassado, fora de moda, que já não se usa.

Vance Packard (1965, p. 51), relaciona três formas pelas quais um produto pode se tornar obsoleto, pela obsolescência de: função (um produto novo executa a função melhor que o existente) ${ }^{3}$, qualidade (o produto é projetado para quebrar ou ser gasto em menor tempo do que o normal) e desejabilidade (quando um produto, que funciona perfeitamente, passa a ser considerado antiquado devido ao lançamento de outro, tornando-o menos desejável).

A obsolescência de desejabilidade, também denominada de obsolescência percebida ou perceptiva, relaciona-se com as estratégias de marketing, vendas e propaganda, em que um produto em sua plena vida útil e perfeito funcionamento é substituído por um novo modelo,

\footnotetext{
${ }^{3}$ A obsolescência de função, também é conhecida por obsolescência técnica ou funcional, é esperada e ocorre devido ao avanço da ciência e tecnologia, como o disco de vinil que foi substituído pelos CDs.
} 
porém com um design diferente, um visual mais agradável, pequenas mudanças funcionais. ${ }^{4}$ Este tipo de obsolescência será aqui tratado como estratégia vinculada ao desperdício e ao estilo de vida hiperconsumista.

A obsolescência de qualidade, mais conhecida como obsolescência programada ou planejada será o objeto deste estudo. Trata-se de uma estratégia na qual desde o desenvolvimento de um produto a indústria já programa e planeja o fim antecipado de sua vida útil, seja pelo desgaste de suas peças ou pela evolução tecnológica que torna obrigatória a compra de um modelo atualizado. O produto é produzido para durar menos. A vida útil do produto, é reduzida propositalmente pela indústria com o intuito de estimular o consumo e movimentar o mercado industrial. Enfim, como afirma Annie Leonard (documentário "A história das coisas", 2007), o produto é "criado para ir para o lixo".5 Os resíduos sólidos gerados são "a ponta do iceberg”, representam apenas a parte facilmente visível do problema, que não se limita ao volume deste lixo, mas está em sua composição. Além disso, a prática da obsolescência programada pelas indústrias acelera a cadeia produtiva, trazendo consequências hoje consideradas insustentáveis nas áreas social e ambiental. ${ }^{6}$

O primeiro caso de obsolescência programada, ainda sem essa denominação, ocorreu em 1924 com a lâmpada elétrica. Neste ano, formou-se o cartel Phoebus, resultado da reunião de um grupo de fabricantes de lâmpadas dos Estados Unidos e da Europa, o qual determinou que a vida útil das lâmpadas deveria ser reduzida de 3.000 para 1.000 horas. $^{7}$ Este fato foi isolado e a prática da obsolescência programada voltará a ser retomada após poucas décadas.

O termo obsolescência programada ou planejada surgiu em 1932 com a publicação de um artigo intitulado "Ending the Depression Through Planned Obsolescence" (Fim da depressão através da obsolescência planejada) de Bernard London. A proposta deste autor para enfrentar a Crise de 1929 era definir a data de obsolescência dos bens de consumo no momento de sua produção, cabendo ao consumidor, após a expiração deste prazo, devolvê-lo

\footnotetext{
${ }^{4}$ Como exemplo de obsolescência perceptiva pode ser citada a moda, que muda o estilo de roupas a cada estação, bem como os celulares, em menos de um ano são lançados novos modelos com poucas funções adicionais.

${ }^{5}$ Sobre o ponto, ver o documentário The Story of Stuff. A história das coisas. Estados Unidos: Annie Leonard, 2007. Disponível em: https://www.youtube.com/watch?v=7qFiGMSnNjw.

${ }^{6}$ Podem ser citados como exemplo: exploração ilegal do trabalho, também conhecido como trabalho escravo, aumento das emissões de $\mathrm{CO} 2$, que contribui para a elevação da temperatura global.

7 Sobre o ponto, ver o documentário The Light Bulb Conspiracy. A história secreta da obsolescência programada. Direção e Produção: Cosima Dannoritzer. Arte France, Televisión Española e Televisió de Catalunya. Espanha: 2010. Disponível em: https://www.youtube.com/watch?v=o0k7UhDpOAo.
} 


\title{
Obsolescência programada e meio ambiente: a geração de resíduos de equipamentos eletroeletrônicos
}

ao Governo, que forneceria um 'vale' a ser utilizado na compra de um novo produto. A proposta de Bernard London não foi aceita em sua época.

Foi no pós-Segunda Guerra Mundial ( $\left.2^{\mathrm{a}} \mathrm{GM}\right)$, com um novo momento de crise econômica, que a obsolescência programada foi realmente colocada em prática, porque representava uma ferramenta que possibilitava alcançar os objetivos da teoria econômica desenvolvimentista: crescimento da economia. Recebeu um conceito adicional, que hoje é conhecido por obsolescência perceptiva, e graças à propaganda os consumidores eram estimulados a desejar produtos novos antes que os antigos atingissem o final de sua vida útil.

Este novo conceito está refletido nas palavras do designer industrial Clifford Brooks Stevens: "incutir no comprador o desejo de possuir algo um pouco mais recente, um pouco melhor, um pouco mais cedo do que é necessário". 8

A estratégia do desperdício é a somatória da obsolescência programada e perceptiva. Não bastaria reduzir a vida útil dos produtos e gerar necessidade de nova compra. Era preciso que os consumidores desejassem o novo produto antes mesmo de sua inutilidade.

Durante a presidência de Dwight Eisenhower (de 1953 até 1961), seu conselheiro econômico, Victor Leboux articulou a principal estratégia para reerguer a economia americana. Suas ideias podem ser extraídas de seu artigo "Price Competition in 1955", publicado no Journal of Retailing:

\begin{abstract}
A nossa economia enormemente produtiva exige que façamos do consumo o nosso modo de vida, que tornemos a compra e uso de bens em rituais, que procuremos nossa satisfação espiritual, a satisfação do nosso ego, no consumo. O status social, a aceitação social e o prestígio agora são medidos por nosso padrão de consumo. O próprio significado e importância de nossas vidas é hoje expressa em termos de consumo. [...] Precisamos que as coisas sejam consumidas, gastas, desgastadas, substituídas e descartadas em um ritmo cada vez maior. [...]. ${ }^{9}$
\end{abstract}

Essa ideia de consumismo foi "vendida" pelo Estado e "comprada" por uma sociedade americana feliz com a paz conquistada e com esperança de prosperidade econômica anunciada pelo governo. Por meio da indústria cultural essa ideia foi amplamente difundida

\footnotetext{
${ }^{8}$ Tradução livre do original: "instilling in the buyer the desire to own something a little newer, a little better, a little sooner than is necessary" (BRADLEY, 2005, p. 548-550).

${ }^{9}$ Tradução livre do original: Our enormously productive economy, demands that we make consumption our way of life, that we convert the buying and use of goods into rituals, that we seek our spiritual satisfactions, our ego satisfactions, in consumption. The measure of social status, of social acceptance, of prestige, is now to be found in our consumptive patterns. The very meaning and significance of our lives today expressed in consumptive terms. [...]We need things consumed, burned up, worn out, replaced and discarded at an ever increasing pace. $[\ldots]$.
} 
pelo mundo. Com a globalização, o padrão de consumo americano passou a ser o padrão de consumo mundial e um padrão ideal a ser alcançado pelos países menos desenvolvidos.

Compreendida as origens da obsolescência programada e o modo como influenciou e alterou os padrões de produção (que abandonou a busca pela qualidade e durabilidade para almejar a alta rotatividade, programando e planejando uma menor vida útil dos produtos) e consumo (instigando na mente dos consumidores a ideia de que consumir o necessário não é suficiente, a felicidade está em consumir em ritmo cada vez maior e mais rápido), será analisada a interligação entre o sistema de produção capitalista globalizado e a sociedade de consumo.

\subsection{O sistema de produção globalizado e a sociedade de consumo}

O consumo entendido como um ato de "adquirir e utilizar bens e serviços para atender às necessidades" (LEONARD, 2011, p. 129) sempre esteve presente na história humana. Entretanto, a forma de consumo alterou-se com o decorrer do tempo. A ruptura ocorreu quando o consumo se transformou em consumismo, a alteração se deu na motivação do consumidor, aquilo que o leva a comprar (BAUMAN 2008, p. 37-39).

Sob o aspecto econômico capitalista, o liberalismo clássico dominou o mundo capitalista antes da crise de 1929, sendo seguido pelo capitalismo baseado no keynesianismo desenvolvimentista, em linhas gerais, baseado na intervenção do Estado na economia, investimento em industrialização para obtenção do crescimento econômico, estado de bem-estar social e sistema de produção fordista, isto é, produção em série para um consumo em massa. Essa época ficou conhecida como a "era de ouro" do capitalismo.

De forma gradual, com a mudança da relação entre os consumidores e os objetos de consumo, houve a passagem da sociedade de produtore ${ }^{10}$ para a sociedade de consumidores.

Consumir se tornou o propósito da existência do indivíduo, onde "querer", “desejar", "ansiar por" um bem ou serviço passou a ser algo de alta relevância na vida da pessoa, que busca repetir esta emoção incontáveis vezes. Esse pensamento passou a sustentar a economia e o convívio humano.

\footnotetext{
${ }^{10}$ Segundo BAUMAN (2008, p. 42-43), a sociedade de produtores, da era sólido-moderna, estava baseada na segurança e estabilidade. Nessa sociedade os desejos eram orientados para aquisição de bens com grande visibilidade na sociedade, o consumo de mercadorias pesadas e duráveis davam status, poder, conforto e principalmente segurança.
} 


\section{Obsolescência programada e meio ambiente: a geração de resíduos de equipamentos eletroeletrônicos}

Zygmunt Bauman (2008, p. 44, 50-51, 71), analisando a sociedade de consumo da era da modernidade líquida, observou que ela é marcada pela instabilidade, liquidez e imediatismo, sendo que o motivo da pressa é a "necessidade de descartar e substituir". O consumismo associa a felicidade não à satisfação de necessidades, mas a "um volume e uma intensidade de desejos sempre crescentes, o que por sua vez implica o uso imediato e a rápida substituição dos objetos destinados a satisfazê-la". ${ }^{11}$

Segundo Annie Leonard (2011, p. 129), o consumismo "refere-se à atitude de tentar satisfazer carências emocionais e sociais através de compras e demostrar o valor pessoal por meio do que se possui”, tem uma consequência que vai além do hiperconsumismo, que conforme a autora, é a utilização de recursos além dos necessários e dos que o planeta é capaz de suprir, perdendo-se de vista o que é importante na vida por uma busca por "coisas". Esta outra consequência é a compulsão por compras.

Ana Beatriz Barbosa Silva (2014, p. 24-27), analisando o aspecto psicológico da mente dos consumidores, identifica dois tipos básicos de consumo: o primário e o secundário. O consumo primário é o necessário à satisfação das necessidades essenciais do indivíduo, vinculado a sua subsistência. O secundário está relacionado ao imaginário, não visando satisfazer nenhuma necessidade real, mas as criadas pela mente do consumidor e é este consumo que "abre as portas do consumismo e da sua vertente patológica: o transtorno do comprar compulsivo".

Este caráter psicológico, que explica a sensação de felicidade causada pelo ato de comprar, foi muito explorado pela propaganda das empresas e pelo discurso do governo.

A mudança do paradigma de consumo não aconteceu de modo natural, foi provocada pelas indústrias com a anuência do próprio governo para reerguer a economia após a $2^{\mathrm{a}}$ Guerra Mundial.

A estratégia do desperdício esteve relacionada com o desejo de hegemonia política, econômica e militar buscado pelo bloco capitalista durante a Guerra Fria, que não mediu consequências para tornar o seu sistema como dominante no mundo.

Com a crise de 1970 surgiu o neoliberalismo que só alcançou o plano político a partir dos anos 1980 e se expandiu para grande parte dos países capitalistas. Com a queda do muro de Berlim, em 1989, que marcou a queda do socialismo, expandiu-se também para os países do leste-europeu.

\footnotetext{
${ }^{11}$ Grifos do autor.
} 
O final da Guerra Fria consolidou, segundo Octavio Ianni (1997, p. 11), "um novo ciclo de expansão do capitalismo, como modo de produção e processo civilizatório de alcance mundial". Tal processo foi denominado globalização e possui diversas dimensões devido sua complexidade.

A globalização em sua dimensão econômica fez o capitalismo neoliberal ganhar o mundo. Atualmente são as grandes empresas multinacionais, orientadas para uma estratégia mundial e apoiadas pelo seu poder econômico (e político) que controlam o mercado e o desenvolvimento econômico mundial (NUNES, 2003, p. 72-73).

Em sua dimensão cultural e ideológica, a globalização representa uma ferramenta de domínio por parte dos produtores da ideologia dominante, uma ideologia de "pensamento único", da massificação dos padrões de consumo e dos padrões de felicidade que acaba por ser imposto à sociedade de consumo como modelo ideal de desenvolvimento, que tem por pretensão anular as culturas e identidades nacionais (NUNES, 2003, p. 72).

Isto geraria, ou melhor, já gerou um grande mercado global padronizado, extremamente previsível e que responderia conforme previsto pelas empresas multinacionais, o que diminui o risco de não aceitação de um produto ou serviço, visto que as diferenças culturais e regionais estariam neutralizadas pela padronização mundial do consumo (e da felicidade).

A alta rotatividade dos produtos aumenta a lucratividade. Consome-se mais e em ritmo cada vez mais rápido. Consumir, ou melhor, hiperconsumir, já faz parte do estilo de vida ou é o ideal a ser alcançado, porque é necessário estar "na moda" porque "todo (o) mundo usa ou tem".

A obsolescência programada atua agora intimamente relacionada à tecnologia. A próxima inovação é incompatível com o produto atual, impossibilitando sua atualização, porque é necessário ter mais memória, mais processador etc. O lançamento de produtos virtuais, como os softwares e aplicativos, força a troca dos produtos físicos (hardwares) porque os modelos antigos não conseguem "rodar" esta nova ferramenta.

A estratégia do desperdício, baseada na obsolescência programada de produtos (industriais e virtuais), foi alavanca ainda mais pela globalização e pelo progresso tecnológico.

\section{RESÍDUOS DE EQUIPAMENTOS ELETROELETRÔNICOS E LEGISLAÇÃO}




\section{Obsolescência programada e meio ambiente: a geração de resíduos de equipamentos eletroeletrônicos}

\subsection{Consequências ambientais do "produzido para ir para o lixo".}

A alteração nos padrões de produção (diminuição da vida útil dos produtos) e de consumo (a felicidade é consumir cada vez mais em menor lapso) em curto período de tempo ocasionou um crescimento industrial de elevado impacto sobre o meio ambiente. As consequências ambientais atingem o planeta como um todo, uma vez que a degradação ambiental não respeita fronteiras. Os danos causados ao meio ambiente em um local acabam por gerar consequências que ultrapassam seus limites territoriais atingindo todo o planeta.

Produziu-se a qualquer custo, sem preocupações ambientais, consideradas custosas. Evitaram-se gastos em nome da vantagem competitiva do negócio. A poluição era encarada como uma decorrência normal do processo industrial e simbolizava progresso, sendo o preço a ser pago pelo desenvolvimento (BARRETO; RIBAS, 2009, p. 20-21).

Os indícios de degradação do meio ambiente se intensificaram e, no final da década de 1960, ocorreram as primeiras reações e estudos sobre suas perigosas consequências para a humanidade.

A preocupação internacional com a crise ambiental fez com que em 1972, na Suécia, fosse realizada a primeira Conferência das Nações Unidas sobre Desenvolvimento Sustentável. A declaração produzida nessa conferência ficou conhecida como Declaração de Estocolmo e é considerada um marco histórico-normativo da proteção ambiental. A partir desta Conferência, as nações "passaram a compreender que nenhum esforço, isoladamente, seria capaz de solucionar os problemas ambientais do Planeta" (MEDEIROS, 2004, p. 41-45).

A expressão “desenvolvimento sustentável” surgiu em 1987, com o relatório "Nosso Futuro Comum” (também conhecido como Relatório Brundtland), da Comissão Mundial sobre Meio Ambiente e Desenvolvimento da Organização das Nações Unidas (ONU), que definiu-o como "aquele que atende às necessidades do presente sem comprometer a capacidade das gerações futuras de atenderem as suas próprias necessidades" (CMMAD, 1999, p. 46).

O compromisso de proteção ao meio ambiente foi reafirmado na Cúpula da Terra (ECO-92, no Rio de Janeiro, 1992). A Declaração do Rio de Janeiro sobre o Meio Ambiente e o Desenvolvimento passou a enfatizar o dever de colaboração entre os Estados e a solidariedade ambiental internacional como essencial para o bem comum da humanidade. Outro documento produzido na Eco-92, a Agenda 21, influenciou diversos ordenamentos 
jurídicos e é considerado um documento de grande importância no âmbito internacional (SILVEIRA; ROCASOLANO, 2010, p. 180).

As consequências ambientais do acelerado ritmo de produção e o hiperconsumismo não se restringem aos Estados produtores e consumidores, afetando todo o globo.

$\mathrm{O}$ efeito estufa e as alterações climáticas não respeitam fronteiras. A emissão mundial de dióxido de carbono (CO2) aumentou 50\% entre 1990 e 2013 e a escassez de água afetou mais de $40 \%$ das pessoas do mundo (PNUD, 2015, p. 82). Os dados disponíveis no site da ONU dedicado ao desenvolvimento sustentável ${ }^{12}$ trazem informações sobre as mudanças climáticas: a temperatura média do planeta aumentou $0,85^{\circ} \mathrm{C}$ (a cada grau de aumento, a produção de grãos reduz 5\%); devido à seca e desertificação, a cada ano são perdidos 12 milhões de hectares (que poderiam produzir 20 milhões de toneladas de grãos). Se a concentração atual de emissão de gases de efeito estufa continuarem no atual ritmo, até o fim do século a temperatura do planeta terá um aumento superior a $1,5^{\circ} \mathrm{C}$. Se em 2050 a população mundial atingir 9,6 bilhões, será necessário o equivalente a três planetas para sustentar o atual estilo de vida.

A estratégia do desperdício é baseada na alta rotatividade de produção, provocada por um aumento no ritmo da demanda: consome-se cada vez mais e cada vez mais rápido. A atual mentalidade de consumo ("comprar, descartar e comprar novamente") e modelo de produção (baseado na obsolescência programada, "criado para ir para o lixo") é incompatível com as metas dos Objetivos do Desenvolvimento Sustentável (ODS) da Agenda 2030 da $\mathrm{ONU}^{13}$, revelando que, consequentemente, são insustentáveis, pois na produção colaboram para o aumento da emissão de gases de efeito estufa, que provocam mudanças climáticas, bem como com o aumento da geração de resíduos sólidos pós-consumo.

Os resíduos sólidos estão sendo "exportados" para países que, além de não produzir tais produtos, possuem uma população que não tem acesso a um mínimo existencial como água potável. ${ }^{14} \mathrm{O}$ aumento da produção de resíduos sólidos, principalmente do lixo eletrônico é um problema detectado pela ONU, que divulgou em 13.05.2015 que: ${ }^{15}$

\footnotetext{
12 A ONU disponibiliza um site dedicado apenas aos ODS (Agenda 2030), apresentando cada um dos 17 objetivos, com seus fatos antecedentes e suas metas: http://www.un.org/sustainabledevelopment/economicgrowth/

${ }^{13} \mathrm{O}$ objetivo $\mathrm{n}^{\circ} 12$ é consumo e produção responsáveis, visando assegurar padrões de produção e de consumo sustentáveis. Para informações mais detalhadas sobre este objetivo vide: https://nacoesunidas.org/pos2015/ ods12/.

${ }^{14}$ Sobre o assunto, vide notícia divulgada pela UNEP (Programa das Nações Unidas para o Meio Ambiente) em 12.05.2015. Disponível em: http://www.unep.org/newscentre/default.aspx?DocumentID=26816\&
} 


\title{
Obsolescência programada e meio ambiente: a geração de resíduos de equipamentos eletroeletrônicos
}

\begin{abstract}
A indústria eletrônica, uma das maiores e que mais crescem no mundo, gera a cada ano até 41 milhões de toneladas de lixo eletrônico de bens como computadores e celulares smartphones. Segundo previsões, este número pode chegar a 50 milhões de toneladas já em 2017.
\end{abstract}

As pautas das discussões internacionais sobre o meio ambiente e desenvolvimento sustentável ainda não contemplaram diretamente a obsolescência programada. São combatidos os seus efeitos, como acima mencionado, mas a obsolescência programada ainda não é vista abertamente como uma das causas da acentuada degradação ambiental.

\subsection{E-lixo: composição, riscos ambientais e ritmo de produção}

A Agência Brasileira de Desenvolvimento Industrial (ABDI) define que equipamentos eletroeletrônicos são "todos aqueles produtos cujo funcionamento depende do uso de corrente elétrica ou de campos eletromagnéticos" (ABDI, 2013, p. 17), que se dividem em quatro grandes categorias: linha branca (refrigeradores e congeladores, fogões, lavadoras de roupa e louça, secadoras, condicionadores de ar), linha marrom (monitores e televisores de tubo, plasma, LCD e LED, aparelhos de DVD e VHS, equipamentos de áudio, filmadoras), linha azul (batedeiras, liquidificadores, ferros elétricos, furadeiras, secadores de cabelo, espremedores de frutas, aspiradores de pó, cafeteiras) e linha verde (computadores desktop e laptops, acessórios de informática, tablets e telefones celulares).

Ao final da vida útil, esses produtos tornam-se resíduos de equipamentos eletroeletrônicos (REE) que são compostos de plásticos, vidros, componentes eletrônicos, mais de vinte tipos de metais pesados e outros, cujas concentrações podem ser microscópicas ou de grande escala, sendo que cada um deles exige um procedimento de extração diferenciado.

Alguns dos materiais encontrados nos REE são metais pesados, parte deles cancerígenos, como alumínio, arsênio, cádmio, bário, cobre, chumbo, mercúrio, cromo, níquel, entre outros (GREENPEACE, 2005, p. 1-14).

A ABDI aponta que a maior parte dos elementos são potencialmente tóxicos e apresentam dois tipos de riscos: contaminação das pessoas que manipulam os REE e contaminação do meio ambiente. No primeiro caso, incluem-se os consumidores que mantém

ArticleID=35021 e http://www.twosides.org.br/BR/Lixo-Eletrnico-coloca-a-saude-em-risco-diz-relatrio-daUNEP. Acessos em: 27.07.2016.

15 Disponível em: https://nacoesunidas.org/onu-preve-que-mundo-tera-50-milhoes-de-toneladas-de-lixoeletronico-em-2017/. Acesso em: 27.07.2016. 
ou utilizam em casa equipamentos antigos, bem como as pessoas envolvidas com a coleta e reciclagem dos REE, sendo essencial que utilizem os equipamentos de proteção individual. Quanto aos riscos de contaminação do meio ambiente, os REE em nenhuma hipótese devem ser depositados diretamente na natureza, junto com os rejeitos orgânicos ou em aterros sanitários, porque o contato de metais pesados com a água gera imediata contaminação do chorume, que multiplica o impacto decorrente de eventual vazamento. Além disso, a penetração no solo desse material pode contaminar lençóis subterrâneos ou acumular-se em seres vivos, com consequências negativas para o ambiente como um todo. (ABDI, 2013, p. 17-18)

O ideal seria que um produto eletroeletrônico somente atingisse o ponto de REE depois de esgotadas as possibilidades de reparo, atualização ou reuso. Entretanto, a grande maioria possui um ciclo de vida curto devido à obsolescência programada aliada com a perceptiva. A indústria ao lançar um novo modelo tecnológico torna incompatíveis as peças de reposição entre os modelos antigos e o novo, além de elevar os preços dessas peças para desestimular o reparo e incentivar a compra de um novo produto. A obsolescência perceptiva ocorre por meio das ações de propaganda, que criam constantemente o desejo pelo novo, pela tecnologia mais avançada, estimulando a troca de produtos que ainda estão em plena vida útil por outro modelo com algumas inovações, como ocorre com os celulares, por exemplo.

Segundo Wanda Maria Risso Günther (2008, p. 110), a geração de REE apresenta um preocupante crescimento, que é fomentado pelos avanços tecnológicos, a alta taxa de descarte, provocada por redução de preço dos produtos, por modismos e estratégia das indústrias de diminuição progressiva da vida útil dos equipamentos (obsolescência programada).

O ritmo de geração do e-lixo tem aumentado progressivamente como aponta os dados estatísticos apresentados pela ONU: a produção mundial de REE em 2014 foi de 41 milhões de toneladas ${ }^{16}$ e estima-se que atingirá 50 milhões de toneladas este ano ${ }^{17}$.

Segundo o relatório "Gestión Sostenible de Residuos de Aparatos Eléctricos y Electrónicos en América Latina”, elaborado pela ONU em parceria com outras organizações internacionais, o Brasil produziu em 2014 a quantia de 1,4 milhão de toneladas, perdendo apenas para os Estados Unidos (7,1 milhões de toneladas) e sendo seguindo pelo México (1

\footnotetext{
${ }^{16} \mathrm{https}$ //nacoesunidas.org/brasil-produziu-14-milhao-de-toneladas-de-residuos-eletronicos-em-2014-afirmanovo-relatorio-da-onu/. Acesso em: 10.03.2017.

${ }^{17}$ Vide item anterior e nota $\mathrm{n}^{\mathrm{o}} 13$.
} 


\section{Obsolescência programada e meio ambiente: a geração de resíduos de equipamentos eletroeletrônicos}

milhão de toneladas) no continente americano. O relatório "Recycling - from e-waste to resources" (UNEP, 2009, p.70) apontou que o Brasil havia produzido em 2005 mais de 368 mil toneladas de lixo eletrônico. Portanto, o crescimento de e-lixo de 2005 a 2014 foi de $380,5 \%$.

Ainda, conforme o referido relatório, a América Latina produziu 3,8 milhões de toneladas de REE, sendo o Brasil responsável por 52\% deste total, seguido pela Argentina (11\%), Colômbia (9\%) e Venezuela (9\%). Considerando a produção per capita de REE na América Latina, a liderança fica com o Chile que produz 9,9 Kg de REE por habitante, sendo seguindo pelo Uruguai $(9,5 \mathrm{Kg} / \mathrm{hab})$, Suriname $(8,5)$, México e Panamá (8,2 cada), Venezuela $(7,6)$, Costa Rica (7,5), Brasil (7,1), Argentina (7,0) e os demais entre 1,8 e 6,5 kg/hab.. Ressalta-se que, em volume total, como o Brasil possui a maior população, lidera a produção do REE com 1,4 milhão de toneladas.

Na América do Sul, dos dez maiores países pesquisados pela ONU (ficaram fora do estudo as Guianas e o Suriname), para elaboração do referido relatório, apenas quatro possuiam marcos regulatórios específicos para REE: Brasil, Colômbia, Equador e Peru.

O marco regulatório sobre REE no Brasil é a Política Nacional de Resíduos Sólidos, Lei $\mathrm{n}^{\mathrm{o}}$ 12.305, de 2 de agosto de 2010, bem como seu Decreto Regulamentador $\mathrm{n}^{\circ}$ 7.404/2010, cabendo ressaltar que ela trata de todos os resíduos sólidos e não apenas dos REE.

\subsection{Política Nacional de Resíduos Sólidos: logística reversa e responsabilidade compartilhada pelo ciclo de vida do produto}

A Política Nacional de Resíduos Sólidos (PNRS), Lei nº 12.305/2010, levou vinte e um anos de discussões no Congresso Nacional até sua aprovação em 02 de agosto de 2010, sendo no mesmo ano, em 23 de dezembro, aprovado seu decreto regulamentador. A PNRS é marcada por uma articulação institucional envolvendo os três entes federados (União, Estados e Municípios), o setor produtivo e a sociedade em geral para buscar soluções para o problema do crescimento da geração de resíduos sólidos, dos mais variados tipos, que comprometem a qualidade de vida.

A PNRS baseia-se no conceito de responsabilidade compartilhada, de modo que cidadãos, governo, setor privado e sociedade civil organizada são responsáveis pela gestão ambientalmente correta dos resíduos sólidos. Como destaca Martins e Murari (2013, p. 3) a essência principiológica extraída do art. $1^{\circ}, \S 1^{\circ}$, da PNRS, é que a sociedade é responsável 
pelo lixo que produz, enfatizando que o lixo passou a ter um novo significado, afastando-se do conceito de objeto sem valor ou utilidade que se joga fora, para ganhar uma nova dimensão com os conceitos de resíduo e rejeito do art. $3^{\circ}$, XV e XVI da PNRS.

Com fundamento nos princípios ambientais constitucionais, na Política Nacional do Meio Ambiente (PNMA) e nos elencados em seu art. $6^{\circ}$, a PNRS busca atingir os objetivos relacionados no art. $7^{\circ}$, por meio de uma série de instrumentos que foram relacionados no art. $8^{\circ}$, sendo que dois deles (inciso III) relacionam-se de forma mais direta com os REE: a logística reversa e a responsabilidade compartilhada pelo ciclo de vida dos produtos.

Logística reversa é, conforme definido no art. $3^{\circ}$, XII, da PNRS, um instrumento de desenvolvimento econômico e social caracterizado por um conjunto de ações, procedimentos e meios destinados a viabilizar a coleta e a restituição dos resíduos sólidos ao setor empresarial, para reaproveitamento, em seu ciclo ou em outros ciclos produtivos, ou outra destinação final ambientalmente adequada.

Os produtos que são sujeitos obrigatoriamente a logística reversa, independente do serviço público de limpeza, estão dispostos no art. 33, entre eles estão os produtos eletroeletrônicos e seus componentes (inciso VI).

Apesar da logística reversa dos REE independer do serviço público de limpeza, o Ministério das Cidades, por meio do Sistema Nacional de Informações de Saneamento (SNIS), que realiza o diagnóstico do manejo dos resíduos sólidos urbanos desde 2002, revelou que em 2014, dos 5.570 municípios $^{18}, 3.765$ participaram da pesquisa do SNIS e as planilhas disponibilizadas demonstram que 762 desses municípios informaram possuir coleta diferenciada de resíduos eletrônicos (por agente público, empresa contratada ou outro meio), ${ }^{19}$ o que representa apenas $13,7 \%$ dos municípios brasileiros.

O art. 56 da PNRS estabeleceu que a implementação da logística reversa deveria ser progressiva e de acordo com o cronograma estabelecido em regulamento. $\mathrm{O}$ decreto regulamentador $\left(\mathrm{n}^{\circ}\right.$ 7.404/2010) em seu art. 18, apenas reforçou a responsabilidade dos fabricantes em realizar a logística reversa no limite da produção que disponibilizar ao mercado interno, com metas progressivas intermediárias e finais, "estabelecidas no

\footnotetext{
${ }^{18}$ Segundo o Instituto Brasileiro de Geografia e Estatística (IBGE), o Brasil passou a ter 5.570 municípios em 2013: http://www.brasil.gov.br/economia-e-emprego/2013/06/cresce-numero-de-municipios-no-brasil-em-2013. ${ }^{19}$ A série história dos diagnósticos de manejo de resíduos sólidos e respectivas planilhas estão disponíveis no site do SNIS: http://www.snis.gov.br/diagnostico-residuos-solidos.
} 


\title{
Obsolescência programada e meio ambiente: a geração de resíduos de equipamentos eletroeletrônicos
}

instrumento que determinar a implementação da logística reversa", isto é, não fixou um cronograma porque depende de acordos setoriais conforme estabelecido nos arts. 23 a 29.

O Ministério do Meio Ambiente (MMA) informa que o sistema de logística reversa dos produtos eletroeletrônicos está em fase de implementação. ${ }^{20} \mathrm{O}$ Sistema Nacional de Informações sobre a Gestão dos Resíduos Sólidos (SINIR), um dos instrumentos da PNRS, informa que das dez propostas de acordo setorial recebidas até junho de 2013, apenas quatro foram consideradas válidas para negociação e que a proposta unificada, recebida em janeiro de 2014, está em negociação, sendo a próxima etapa a consulta pública. ${ }^{21}$

A Agência Brasileira de Desenvolvimento Industrial (ABDI) publicou em 2013 uma análise de viabilidade técnica e econômica da implementação da logística reversa de equipamentos eletroeletrônicos que apontou como benefícios desta implementação vão além do impacto ambiental, envolvendo benefícios sociais e econômicos:

\begin{abstract}
No que tange a geração de empregos formais, estima-se o potencial de criação de cerca de 10 a 15 mil posições de trabalho [...]

Em termos financeiros esse volume de sucata gera um crescimento potencial do mercado de $\mathrm{R} \$ 700$ milhões. [...]

Ainda, na linha dos impactos ambientais, há que se destacar a potencial redução de emissão de $\mathrm{CO} 2$ pelo uso de materiais reciclados a partir do sistema de logística reversa dos REEE. (ABDI, 2013, p. 99-00)
\end{abstract}

Apesar de ainda não implementada, a Associação Brasileira da Indústria Elétrica e Eletrônica (ABINEE) fundou em 2016 a GREEN Eletron - Gestora para Logística Reversa de Equipamentos Eletroeletrônicos, que possui como associadas onze fabricantes de produtos eletrônicos com atuação no Brasil $^{22}$ e permite a associação de outras empresas do setor, mesmo que não associadas à ABINEE. O objetivo principal da GREEN Eletron é auxiliar as empresas no atendimento à PNRS, propondo criar um sistema coletivo para operacionalizar a logística reversa de suas associadas.

Responsabilidade compartilhada pelo ciclo de vida dos produtos é, conforme definido no art. $3^{\circ}$, XVII, da PNRS, o conjunto de atribuições individualizadas e encadeadas dos fabricantes, importadores, distribuidores e comerciantes, dos consumidores e dos titulares dos serviços públicos de limpeza urbana e de manejo dos resíduos sólidos, para minimizar o

\footnotetext{
${ }^{20}$ Sobre sistema de logística reversa implementada e em fase de implementação estão disponíveis no site do MMA: http://www.mma.gov.br/cidades-sustentaveis/residuos-perigosos/logistica-reversa/sistemas-emimplantação.

${ }^{21}$ O site do SINIR não disponibiliza maiores informações sobre logística reversa do REE: http://www.sinir.gov. $\mathrm{br} /$ web/guest/logistica-reversa.

${ }^{22}$ As atuais associadas da GREEN Eletron são: Apple, Asus, Dell, Flex, Epson, HP, Lenovo, Microsoft, Moto, Positivo e Samsung. Disponível em: https://www.greeneletron.org.br/.
} 
volume de resíduos sólidos e rejeitos gerados, bem como para reduzir os impactos causados à saúde humana e à qualidade ambiental decorrentes do ciclo de vida dos produtos.

No caso dos REE, a responsabilidade dos fabricantes, importadores, distribuidores e comerciantes encontra-se principalmente relacionada à logística reversa, devendo receber e processar os REE. O setor público, apesar de a logística reversa independer de serviço de coleta público (art. 33, PNRS), deve promover a informação ao consumidor e principalmente a educação ambiental, que é um dos instrumentos da PNRS (art. $8^{\circ}$, VIII). O consumidor é responsável pela disposição correta dos REE que gera, não podendo descartá-los no lixo comum. A responsabilidade dos consumidores está prevista no art. $6^{\circ}$ do Decreto $\mathrm{n}^{\circ}$ $7.404 / 2010$.

A PNRS vigora desde agosto de 2010, mas no que se refere aos REE ela não apresenta a eficácia desejada porque ainda não foi definitivamente implementada. $\mathrm{O}$ acordo setorial, até fevereiro de 2017, data de conclusão da presente pesquisa, ainda não havia sido assinado.

No que tange a obsolescência programada, a PNRS não aborda diretamente o tema, apenas define em seu art. $3^{\circ}$, XIII, o que são padrões sustentáveis de produção e consumo, apresentando como um dos seus objetivos o "estímulo à adoção de padrões sustentáveis de produção e consumo de bens e serviços" (art. $7^{\circ}$, III).

\section{CONCLUSÃO}

A obsolescência programada nasceu como uma proposta para solucionar a crise econômica de 1929 e ressurgiu com força total após a $2^{\text {a }}$ guerra mundial para promover o crescimento econômico e o capitalismo, entretanto transformou-se em estratégia empresarial (comprar, descartar, comprar) que passou a sustentar as indústrias. Como consequência, promoveu o surgimento da sociedade de consumo e um estilo de vida hiperconsumista.

Esse ciclo vicioso criado pela estratégia do desperdício, atualmente traz mais problemas do que soluções, uma vez que o ritmo acelerado de produção aumenta a exploração de recursos naturais, eleva as emissões de gases de efeito estufa, aumenta o consumo de energia e de água, incentivando um consumo cada vez mais rápido, que gera uma quantidade cada vez maior de resíduos sólidos.

A evolução tecnológica avança muito mais rapidamente do que acontecia há duas décadas. No setor de computação e comunicação, o ritmo de evolução é exponencial. 


\section{Obsolescência programada e meio ambiente: a geração de resíduos de equipamentos eletroeletrônicos}

A obsolescência programada e perceptiva dos produtos eletroeletrônicos está diminuindo cada vez mais a vida útil destes produtos, sejam pela quebra ou defeito que ocorrem antes do esperado, seja pelo lançamento do novo modelo ou versão que diminui o desejo pelo antigo, que passa a ser descartado para a aquisição de um novo.

A rápida evolução dos produtos eletroeletrônicos acelerou o descarte desses produtos em tempo cada vez menor, gerando como consequência um crescimento acentuado dos resíduos de equipamentos eletroeletrônicos, o que passou a ser uma preocupação mundial. Este modelo de produção, que incentiva o descarte, e a mentalidade de consumo, que não se preocupa com consequências, mas apenas com a felicidade momentânea da nova aquisição, são incompatíveis com as metas dos Objetivos do Desenvolvimento Sustentável (ODS) da Agenda 2030 da ONU, que buscam padrões de consumo e produção responsáveis.

A composição dos REE contém diversos elementos prejudiciais ao meio ambiente e à saúde humana, entre eles diversos metais pesados que são cancerígenos. Portanto, o ideal seria que um produto eletroeletrônico fosse considerado REE apenas depois de esgotadas as possibilidades de reparo, atualização e reuso.

Os REE não podem ser confundidos com lixo (coisa sem valor ou utilidade) porque podem passar pelo processo de reciclagem e reutilização (art. $3^{\circ}$, XIV e XVII). Este mercado de reaproveitamento dos REE é economicamente viável e potencialmente lucrativo, conforme estudo realizado pela ABDI.

A PNRS e seu decreto regulamentador entraram em vigor em 2010 e representam um marco regulatório importante para preservação ambiental e qualidade de vida, em sintonia com o art. 225 da Constituição Federal. Entretanto, alguns acordos setoriais que são necessários para a efetiva implementação dos instrumentos da PNRS ainda não foram concluídos, adiando consequentemente sua obrigatoriedade.

No caso dos produtos eletroeletrônicos há a previsão da implementação da logística reversa pelas empresas, no entanto, após sete anos, o acordo setorial ainda não foi assinado, com previsão para que isso ocorra neste ano de 2017. Enquanto isso, o volume de e-lixo no Brasil saltou de 368 mil toneladas em 2005 para 1,4 milhões de toneladas em 2014, um aumento de 380,5\%. Enquanto o acordo setorial dos REE não estiver concluído e implementado, a PNRS não apresentará eficácia para solucionar a crescente geração dos REE.

A logística reversa para os REE é incipiente até o momento. A empresa ainda não está obrigada a receber o produto em desuso, bem como o consumidor não está obrigado e 
informado sobre o correto descarte deste tipo de resíduo. A coleta seletiva de REE é realizada apenas por $13,7 \%$ dos municípios brasileiros.

A responsabilidade compartilhada pelo ciclo de vida dos produtos exige atitudes individualizadas e encadeadas de cada um dos atores envolvidos (empresas, consumidores e serviços públicos de limpeza). Cada um tem seu papel a cumprir, mas para isso é necessário que cada um saiba o que deve ou não fazer. Para que a responsabilidade compartilhada seja possível é imprescindível que haja informação e orientação.

No caso dos REE, a conscientização dos consumidores é incipiente, sendo necessária não apenas a informação sobre a obrigatoriedade do descarte adequado, bem como sobre as consequências ambientais da destinação incorreta e das contribuições da reutilização e reciclagem deste tipo de resíduo sólido, para que ele possa repensar sobre seus hábitos de consumo e refletir sobre suas consequências.

A efetiva diminuição dos resíduos sólidos, em especial dos REE, não está apenas na coleta seletiva, logística reversa e responsabilidade compartilhada pelo ciclo de vida dos produtos, mas em uma educação ambiental que promova um consumo e produção responsáveis, capazes de alterar os atuais padrões de produção e consumo, baseados no descarte antecipado dos produtos, para padrões responsáveis que se pautem nos 3Rs (reduzir, reutilizar e reciclar), como forma de alcançar o desenvolvimento sustentável e a preservação do meio ambiente e da qualidade de vida das futuras gerações.

\section{REFERÊNCIAS}

AGÊNCIA BRASILEIRA DE DESENVOLVIMENTO INDUSTRIAL (ABDI). Logística reversa de equipamentos eletroeletrônicos: análise de viabilidade técnica e econômica. ABDI: Brasília, 2013.

BARRETO, Luiz Geromel; RIBAS, Renata. Mudança nos padrões de produção e consumo. Curitiba: CREA-PR, 2009. p. 20-21. (série publicações temática do CREA-PR. vol $3)$.

BAUMAN, Zygmunt. Vida para o consumo: a transformação das pessoas em mercadoria. Tradução de Carlos Alberto Medeiros. Rio de Janeiro: Zahar, 2008.

BRADLEY, Betsy H. Industrial Strength Design: How Brooks Stevens Shaped Your World (review). Comentário ao livro de Adamson, Glenn. Industrial strength design: how 
Brooks Stevens shaped your world. Enterprise \& society. Cambridge, v. 6, n. 3, p. 548-550, september. 2005. Disponível em: <https://muse.jhu.edu/login?auth=0\&type=summary\&url=/ journals/enterprise_and_society/v006/6.3bradley.html> Acesso em 20.11.2015.

BRASIL. Constituição da República Federativa do Brasil, de 1988.

Política Nacional do Meio Ambiente, Lei 6.938, de 31 de agosto de 1981.

Política Nacional de Resíduos Sólidos, Lei 12.305, de 02 de agosto de 2010.

Decreto regulamentador da PNRS, Decreto 7.404, de 23 de setembro de 2010.

COMISSÃO MUNDIAL SOBRE MEIO AMBIENTE E DESENVOLVIMENTO (CMMAD). Nosso futuro comum. Rio de Janeiro: Fundação Getulio Vargas, 1988.

GREEN-ELETRON. Eletrônicos usados merecem um novo começo. Disponível em: https://www.greeneletron.org.br/. Acesso em: 10.03.2017.

GREENPEACE. Toxic tech: chemicals in electronics. 20.05.2005. Disponível em: http://www.greenpeace.org/international/en/publications/reports/toxic-tech-chemicals-in-elec/ Acesso em: 01.03.2017.

GÜNTHER, Wanda Maria Risso. Resíduos sólidos no contexto da saúde ambiental. Tese de livre docência. Departamento de Saúde Pública da USP. Especialidade: Avaliação, prevenção e controle da poluição por resíduos sólidos, 2008.

IANNI, Octavio. A era do globalismo. 4. ed. Rio de Janeiro: Civilização Brasileira, 1999.

LEBOUX, Victor. Price Competition in 1955. Disponível em: < http://www.gcafh.org/ edlab/Lebow.pdf > Acesso em: 10.01.2016.

LEONARD, Annie. A história das coisas: da natureza ao lixo, o que acontece com tudo que consumimos. Tradução de Heloisa Mourão. Jorge Zahar Editor, 2011. ed. digital. ePub: Simplíssimo Livros.

LONDON, Bernard. Ending the Depression Through Planned Obsolescence. Disponível em: < http://www.murks-nein-danke.de/blog/download/London_(1932)_Ending_the_ depression_through_planned_obsolescence.pdf > Acesso em: 10.01.2016.

MARTINS, Juliana Xavier Fernandes; MURARI, Gabriel Garcia. Os princípios ambientais na política nacional de resíduos sólidos: a questão principiológica. In: BECHARA, Erika (org.). Aspectos relevantes da política nacional de resíduos sólidos: Lei $n^{\circ}$ 12.305/2010. São Paulo: Atlas, 2013. cap. 1. p. 1-30.

MEDEIROS, Fernanda Luiza Fontoura de. Meio ambiente: direito e dever fundamental. Porto Alegre: Livraria do Advogado, 2004.

MEZZAROBA, Orides; MONTEIRO, Cláudia Sevilha. Manual de metodologia da pesquisa no direito: atualizado de acordo com as últimas normas da ABNT. 6. ed. São Paulo: Saraiva, 2014. 
MINISTÉRIO DO MEIO AMBIENTE (MMA). Logística reversa: sistema em implementação. Disponível em: http://www.mma.gov.br/cidades-sustentaveis/residuosperigosos/logistica-reversa/sistemas-em-implantação. Acesso em: 10.03.2017.

NUNES, António José Avelãs. Neoliberalismo e direitos humanos. Rio de Janeiro: Renovar, 2003.

ORGANIZAÇÃO DAS NAÇÕES UNIDAS (ONU). The Millennium Development Goals Report 2015. Junho/2015a. Objetivos do Desenvolvimento do Milênio (ODM). Disponível em: https://nacoesunidas.org/wp-content/uploads/2015/07/MDG-2015-June-25.pdf. Acesso em: 06.08.2016.

Objetivos do Desenvolvimento Sustentável (ODS). Setembro/2015b. Transformando nosso nundo: a agenda 2030 para o desenvolvimento sustentável. Disponível em: https://nacoesunidas.org/wp-content/uploads/2015/10/agenda2030-pt-br.pdf. Acesso em: 06.08.2016.

. Declaração de Estocolmo. Jun/1972. Disponível em: http://www.onu. org.br/rio20/img/2012/01/estocolmo1972.pdf. Acesso em 27.07.2016.

Declaração do Rio sobre meio ambiente e desenvolvimento. Rio de Janeiro, 1992.Disponível em: http://www.onu.org.br/rio20/img/2012/01/rio92.pdf Acesso em: 27.07.2016.

Agenda 21. Rio de Janeiro, 1992. Disponível em: http://www.mma. gov.br/responsabilidade-socioambiental/agenda-21/agenda-21-global. Acesso em: 27.07.2016.

ONU preve que mundo terá 50 milhões de toneladas de lixo eletrônico em 2017. 13.05.2015c. Disponível em: https://nacoesunidas.org/onu-preve-que-mundo-tera-50-milhoesde-toneladas-de-lixo-eletronico-em-2017/. Acesso em: 27.07.2016.

Brasil produziu 1,4 milhão de toneladas de resíduos eletrônicos em 2014, afirma novo relatório da ONU. 20.05.2015. Disponível em: https://nacoesunidas.org/brasilproduziu-14-milhao-de-toneladas-de-residuos-eletronicos-em-2014-afirma-novo-relatorio-daonu/. Acesso em: 10.03.2017.

Gestión sostenible de residuos de aparatos eléctricos y electrónicos en América Latina. 2016. Disponível em: http://wftp3.itu.int/pub/epub_shared/TSB/2016-Integratedmngnt-ES/files/downloads/RAEE_Gestion\%20integral\%20y\%20eliminacion-395429-Normal -S.pdf. Acesso em: 10.03.2017.

PACKARD, Vance. A estratégia do desperdício. São Paulo: Ibrasa, 1965.

PORTAL BRASIL. Cresce número de municípios no Brasil. 30.07.2014. Disponível em: http://www.brasil.gov.br/economia-e-emprego/2013/06/cresce-numero-de-municipios-nobrasil-em-2013. Acesso em: 10.03.2017.

PROGRAMA DAS NAÇÕES UNIDAS PARA O MEIO AMBIENTE (PNUMA). Lixo eletrônico coloca a saúde em risco diz relatório da UNEP. 12.05.2015. Disponível em: 
http://www.unep.org/newscentre/default.aspx?DocumentID=26816\&ArticleID=35021

http://www.twosides.org.br/BR/Lixo-Eletrnico-coloca-a-saude-em-risco-diz-relatrio-daUNEP. Acessos em: 27.07.2016.

PROGRAMA DAS NAÇÕES UNIDAS PARA O DESENVOLVIMENTO (PNUD). Relatório do desenvolvimento humano 2015: o trabalho como motor do desenvolvimento humano. Disponível em: https://nacoesunidas.org/wp-content/uploads/2015/07/MDG-2015June-25.pdf. Acesso em: 06.08.2016.

SILVA, Ana Beatriz Barbosa. Mentes consumistas: do consumismo à compulsão por compras. ed. digital. São Paulo: Globo, 2014.

SILVEIRA, Vladmir Oliveira da; ROCASOLANO, Maria Mendez. Direitos humanos: conceitos significados e funções. São Paulo: Saraiva, 2010.

SISTEMA NACIONAL DE INFORMAÇÕES DE SANEAMENTO (SNIS). Diagnóstico resíduos sólidos. Disponivel em: http://www.snis.gov.br/diagnostico-residuos-solidos. Acesso em: 10.03.2017.

SISTEMA NACIONAL DE INFORMAÇÕES SOBRE A GESTÃO DOS RESÍDUOS SÓLIDOS (SINIR). Logística reversa. Disponível em: http://www.sinir.gov.br/ web/guest/logistica-reversa. Acesso em: 10.03.2017.

The Light Bulb Conspiracy. A história secreta da obsolescência programada. Direção e Produção: Cosima Dannoritzer. Arte France, Televisión Española e Televisió de Catalunya. Espanha: 2010. Disponível em:https://www.youtube.com/ watch?v=o0k7UhDpOAo. Acesso em 20.11.2015.

The Story of Stuff. A história das coisas. Estados Unidos: Annie Leonard, 2007. Disponível em: https://www.youtube.com/watch?v=7qFiGMSnNjw. Acesso em 20.02.2017.

UNITED NATIONS ENVIRONMENT PROGRAMME (UNEP). Recycling - from e-waste to resources: Sustainable Innovation and Technology Transfer Industrial Sector Studies. July 2009. Disponível em: http://issuu.com/recicloambiental/docs/onu_ewaste/7?e=0. Acesso em:10.03.2017 